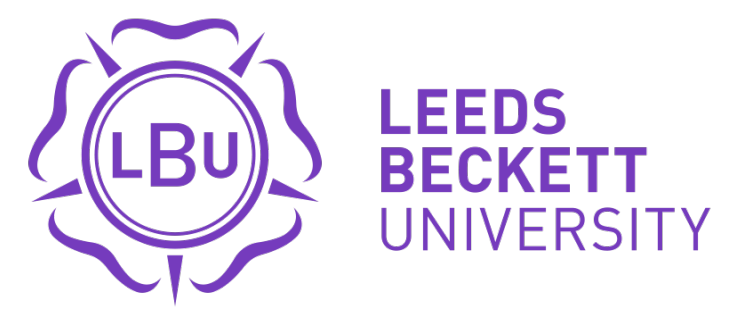

Citation:

Wiesenberg, M and Tench, R (2019) Deep strategic mediatization: Organizational leaders' knowledge and usage of social bots in an era of disinformation. International Journal of Information Management. p. 102042. ISSN 0268-4012 DOI: https://doi.org/10.1016/j.ijinfomgt.2019.102042

Link to Leeds Beckett Repository record:

https://eprints.leedsbeckett.ac.uk/id/eprint/6372/

Document Version:

Article (Accepted Version)

The aim of the Leeds Beckett Repository is to provide open access to our research, as required by funder policies and permitted by publishers and copyright law.

The Leeds Beckett repository holds a wide range of publications, each of which has been checked for copyright and the relevant embargo period has been applied by the Research Services team.

We operate on a standard take-down policy. If you are the author or publisher of an output and you would like it removed from the repository, please contact us and we will investigate on a case-by-case basis.

Each thesis in the repository has been cleared where necessary by the author for third party copyright. If you would like a thesis to be removed from the repository or believe there is an issue with copyright, please contact us on openaccess@leedsbeckett.ac.uk and we will investigate on a case-by-case basis. 


\section{Deep Strategic Mediatization: Organizational Leaders' Knowledge and Us- age of Social Bots in an Era of Disinformation}

\section{Introduction}

In 2016 both the US presidential and Brexit political campaigns and counter campaigns marked a new era in disinformation and propaganda campaigning on the internet and more explicitly the social web. Compared to former disinformation campaigning, this time the different camps used computational propaganda - also called social (ro-)bots. Examples of these software bots are chatbots or other algorithms that are designed with the specific purpose of holding conversations with humans and were envisioned already by Alan Turing in 1950 (cf. Paoli, 2017). By calling them "social" indicates human interaction with such (ro-)bots wittingly or unwittingly in the digital sphere and primarily on social media. Hence, Ferrara et al. (2016, p. 96) define social bots as "a computer algorithm that automatically produces content and interacts with humans on social media, trying to emulate and possibly alter their behavior." Although bots are programmed to provide all kinds of useful services (e.g., bots that "automatically aggregate content from various sources, like simple news feeds" (ibid.) or provide automatic email responses or chats to respond to enquiries, or to assist in customer care or marketing services), they can be destructive too (e.g., when they spread unverified information or rumors to shape the norms adopted by social media users) (Ross et al., 2019).

Most research in information and communication management and sub disciplines like public relations, marketing or political communication concentrate on the "computational propaganda" side by referring to and investigating the field of political communication, be it the US presidential election in 2016 or other elections recently carried out in Europe, Latin America and Asia (Bessi \& Ferrara, 2016; Bolsover \& Howard, 2017, 2018; Ferrara, 2017; Kapoor \& Dwivedi, 2015; Stella, Ferrara, \& Domenico, 2018; Woolley \& Howard, 2018). Moreover, the relevance and rationale of automated communication based on algorithms is prevalent in academic and professional literature in the field of marketing and customer care (cf. Appel, Grewal, Hadi, \& Stephen, 2019; Gentsch, 2018; Heimbach, Kostyra, \& Hinz, 2015; Kumar et al., 2013) as well as recently in the realm of public relations (Collister, 2015a, 2015b; Phillips, 2015). Besides the insights based on Wiesenberg, Zerfass, and Moreno (2017) that primarily investigate the practices of automated communication in general (algorithmic tools for content distribution, adaptation, and creation) there is a dearth of both theoretical concepts and empirical knowledge about the perception and usage of social bots from the organizational perspective.

From a theoretical standpoint automation in general and specifically social bots can be linked to the concept of deep mediatization, as introduced by Couldry and Hepp (2017). They argue that media today is highly interwoven in all kinds of social processes and therefore constructions of reality are impacted by the "latest wave(s) of digitalization and datafication" (p. 34). Based on this idea, Zerfass, Verčič, and Wiesenberg (2016) introduced the concept of strategic mediatization to describe new forms of mediatized content strategies, especially in corporate communications. However, with highlighting deep mediatization, Couldry and Hepp (2017) refer to the advanced spread of digital media and vice versa to the fact that the social world "very deeply relies on these technologically based communication media" (Hepp et al., 2018 , p. 6). And because digital media relies finally on data, "the very elements and building blocks from which a sense of the social is constructed become themselves founded on technologically based processes of mediation" (ibid.). By discussing automation (building content on data and algorithms) and more specifically the use and potential application of social bots to produce or distribute content for strategic communication and information purposes, this paper challenges the disinformation bias of social bots in recent papers and instead introduces the concept of deep strategic mediatization. Moreover, results from a European survey of communication and marketing leaders provides empirical evidence on the status quo of social bots 
usage and therefore some first indications on the concept of deep strategic mediatization being introduced here.

\section{Theoretical background}

\subsection{Origins and direction for social bots}

In contextualising the debates about social bots there is evident ambiguity and differing interpretations of what they theoretically are and practically do. The research on social bots in the broader realm of communication and information management is quite diverse and ranges from journalism and political communication to (service) marketing and advertising, as well as technical communication and linguistics. Research in the field of strategic communication and information management has only touched on this topic and as such far more traditionally (cf. Xu \& Kaye, 1997), even though recently the topic has become more prominent in the area of artificial intelligence (AI). Therefore, the following literature review presents a broader perspective into the status quo regarding social bots.

Most of this research has been published in the field of political communication. For example, the "Computational Propaganda Research Project" concentrates primarily on research on "how tools like social media bots are used to manipulate public opinion by amplifying or repressing political content, disinformation, hate speech, and junk news" (Oxford Internet Institute, 2018) in different European, Asian and American countries (Woolley \& Howard, 2018). The first research in the field of automation and politics was published by Hersh and Schaffner (2013) and Nickerson and Rogers (2014) who analyzed algorithmic-based US election campaigns in 2012. Research into the 2016 US election campaigns for democrats, republicans and anonymous third parties indicate that the heavy usage of social bots aimed to manipulate the discourse and re-create, destroy or support specific meanings (Bessi \& Ferrara, 2016; Ferrara et al., 2016; Howard, Woolley, \& Calo, 2018; Woolley, 2016; Woolley \& Howard, 2016a, $2016 b)$. However, comparing the usage of social bots in the political realm of different countries leads to the conclusion that existing laws, institutions and social norms in certain countries and regions facilitate and others restrict social bot usage (Woolley \& Howard, 2018).

Studies concentrate on network analysis, mainly focusing on Twitter and Facebook and how robots try to reshape, support or destroy meanings and therefore became a threat for discourse and meaning creation in the public sphere. Many of the highlighted bot examples focus on negative applications such as spam, sabotage, cyberwarfare, public opinion manipulation, advocacy and nullifying dissent as well as confusing political debate (Bradshaw \& Howard, 2017; Wooley \& Howard, 2016). In their content analyses of the Washington Post, the New York Times and USA Today, Fürst and Oehmer (2018) found some indications that social bots have a specific influence on the public agenda. According to the authors, the rationale behind this is the increasing news factor of public vibrancy, which was being strongly influenced by social bots.

In many of these reviews, bots are discussed as a coherent category even though work has been done to define and create distinctions between different types. Howard, Wooley and Calo (2018) for example introduce two simple categorical types of bot: legitimate and malicious. Yang et al. (2018) also attempt to discuss characteristics of bots but really present further examples such as (1) simple bots that post content, (2) sophisticated bots that impersonate humans, (3) bots designed to form an audience, (4) bots that create false followers for financial reward, (5) botnets which coordinate and act as multiple disseminators of the same content to create an impression of false popularity.

Another kind of classification has been suggested by Ferrara, Varol, Davis, Menczer, and Flammini (2016). By presenting an overview of different forms of how to apply social bots, they differentiate between a) identify and follow users on social networks, b) like, forward or retweet posts/tweets, c) respond, reply or comment on posts/tweets, and d) create content and post/tweet it on social networks. Hence, they define a social bot as "a computer algorithm that 
automatically produces content and interacts with humans on social media, trying to emulate and possibly alter their behavior." (p.96). Nevertheless, the restriction on social media alone is criticized by Grimme, Preuss, Adam, and Trautmann (2017) referring to the "imitation of human communication (behavior)" as a "key feature of social bots" (p. 280). However, they understand social bots "as a high-level concept which comprises many types of specific bots" like "fully automated as well as partly human-steered bot action, autonomous action (agent-like), an orientation towards a goal, multiple modes of communication, and a wider ecosystem (all online media)" (ibid.). Grimme et al. acknowledge they are referring primarily to the realm of social media. Therefore, we argue that social bots are primarily used in social media, but can also be apparent in other social networks like WhatsApp or Skype where one-to-many communication can be prevalent as well (this is what differentiates chat bots from social bots).

\subsection{Content creation and distribution in times of deep mediatization}

According to Ihlen and Pallas (2014), the literature on corporations and other types of organizations concerning mediatization is scarce. In this context, they refer foremost to media relations and the necessity of media coverage. However, focusing on broader perspectives like new concepts of content creation and delivery, Zerfass et al. (2016) refer to new digital media strategies that "blurs what used to be constitutive borders between advertising (paid publicity) and media relations (earned publicity), mass media, and other noncore media organizations, who are creating content either as sources or multipliers" (p. 502). They focus on the one hand on the new paradigm of strategic communication by discussing the blurring boundaries between "the traditional communication disciplines in organizations" (ibid.). On the other hand, they refer "explicitly to the idea of mediatization" not primarily from an institutional perspective with its inherent logic, but following Couldry and Hepp (2017) as well as Holtzhausen and Zerfass (2015) referring to "the constitutive model of communication focuses on the co-construction of meaning" (Zerfass et al., 2016, p. 502). However, the concept of deep mediatization was not taken into consideration before in the context of strategic communication and public relations.

Mediatization as a concept is highlighted by Couldry and Hepp (2017) as a meta-process of increasing penetration of space, time and social reality through technologies of mediated communication. Therefore, constructions of meanings are interrelated, manifold and in part even contradictory because "media have changed the reference-points of human practices so dramatically, it is now obvious not only that the social world is something constructed by us as humans, but that these processes of construction can only be understood ... with ... the increasing social relevance of technologies of mediated communication." (ibid., p. 16) Media therefore constitute not only the social world, but also contributes significantly to transform all kinds of communications, be it public, private or even illicit and secret.

To illustrate these fundamental shifts, they refer to 'waves of mediatization' like the 'mechanization', the 'electrification' or the 'digitalization' that brought qualitative changes to the whole media environment. Traditional analogue media became digital and new digital media like social media platforms arose and have now become omnipresent. This new kind of digital media production brought a fundamental shift in agency. While former media corporations primarily influenced the public agenda and therefore public discourse, today everybody with internet access and a mobile device is able to participate in the World Wide Web and contribute to the public agenda. That is especially true for corporations (e.g., Red Bull or Virgin) that have become media outlets on their own (Zerfass et al., 2016).

The more that humans and organizations use digital communication technologies, the more they will leave 'digital traces' (Karanasios et al., 2013). By referring to the term 'datafication' van Dijck (2014) makes clear that digital media are no longer only a means of technologically facilitated communication. Communication via digital media creates new realities by communications on the one hand and on the other, they become a "means of producing data 
that can be delinked from the specific acts of communication and can be used for very different purposes." (Hepp et al., 2018, p. 5) The purposes and ways these data are used is processed by algorithms in automatized ways controlled by agents that own the website, service or platform. Hence, processes of social construction through media no longer refer only to human communication, but also to the "automatized accumulation and calculation of the data we produce while we use digital devices for communication." (ibid., p. 6) Having said this, the social world today becomes gradually constructed through datafication. This advanced stage of mediatization, due to the results of digitalization and datafication, is referred to as deep mediatization.

Viewed from the media stakeholder perspective, reflective organizations have understood that in the new paradigm reality is based on not only their evaluating and listening to acts of communication from diverse stakeholders, but also interacting and creating with them. In addition, they constantly monitor and process their digital traces and make sense of these "huge volumes and streams of different forms of data from diverse internal and external sources" (Wiesenberg et al., 2017, p. 96) - termed 'big data'. Both the acts of communication as well as predictive analytics of these digital traces (data) gave birth to new algorithms that (semi) automatically produce and distribute content at the right moment via the right channel to the right user (be it human or another robot). Hence, digital acts of communication become fundamentally diverse (e.g., human-human, human-robot or robot-robot communication). All of them participate today in networked interactions and create all kinds of meanings. However, very little is known regarding the agents behind these specific practices of automated communication or the perception of these practices from the communicators' perspective.

Considering the transformation of deep mediatization due to digitalization and datafication, it is quite surprising that bot communication (the fully automated production and distribution of content by robots) has been largely neglected in organizational communication and specifically by the custodians of messaging in the area of public relations and strategic communication. However, the concept of deep mediatization offers new perspectives for scholars and practitioners alike. Zerfass et al. (2016) introduced the concept of strategic mediatization, referring to the blurring boundaries between the different subfields of strategic communication and mediatization. Moreover, the latest research and projects in the field of big data and automation in strategic communication (Wiesenberg et al., 2017) demonstrate the necessity to broaden the concept of strategic mediatization by considering not only acts of communication and content strategies (including listening). Using semi- or fully automated services based on algorithms that process data for organizational purposes demonstrate that online service providers and platforms create and transform social reality. The concept of deep strategic mediatization refers therefore also to the digital artefacts constantly produced by digital acts (not only acts of communication) which are increasingly processed and analyzed by organizations and their communication or marketing departments. With this concept, strategic communication and deep mediatization might foster a new research paradigm taking into account both of these acts of (mediated) communication as well as digital artefacts and acts used for strategic automated communication like social bots. From this perspective, it seems quite promising to examine how social bots are perceived and used because they are a specific outcome of automated communication based on digital traces, especially on social media. This paves the way to explore the impact on and implications for a first glimpse of deep strategic mediatization.

\subsection{Social bots between computational propaganda and helpful services}

As already demonstrated above, most research in the political realm focuses on social bots as "computational propaganda". Hence, the view of social bots is mostly negatively connoted and is portrayed as a threat for societies, democracy and the public sphere. This negative connotation of social bots is also present in research that analyses the news coverage of traditional media outlets, especially during election campaigns. However, as Ross et al. (2019) recently demonstrated in a simulation, social bots can be used far beyond the political realm. The authors 
conclude that social bots can influence and manipulate online opinion formation especially those of minorities: "A relatively small number of bots was sufficient to sway the opinion climate in the direction of the opinion supported by the bots, triggering a spiral of silence process that ultimately led to the bot opinion becoming accepted as the perceived majority opinion." ( $p$. 16) This leads to the conclusion that social bots can and are being used for different purposes and in different contexts.

Negative connotations like those held in the political realm are less prevalent in journalism research. Bradshaw (2018, p. 310) for example differentiates between; bots that automatically publish updates on social media accounts or smartphone apps by receiving new information from a (push) feed; bots that supply specific suggestions of news articles; or bots that attempt to provide answers like FAQs or WhatsApp-Bots. Moreover, by referring to Lokot and Diakopoulos (2016) as well as Woolley (2016) he explains how social bots act as automated social actors interacting with users or content in various ways not only in social networks but also in comments sections of online news sites or forums. The main question this raises is about ownership and therefore agency. Messenger bots, for example, are seen as highly relevant for the future of news distribution from the journalistic side to spread their news in different online channels (Anderson, 2017). However, they also express concern and the potential for harm when it comes to automated accounts (Larsson \& Hallvard, 2015). The journalism perspective demonstrates a broader view on social bots and takes into account the challenges and risks as well as the positive possibilities bots might have for journalism and specifically for content creation and distribution.

In the area of marketing and advertising automated messaging and distribution of sales content has a long tradition and includes customized and automated e-mail marketing campaigns (Malhotra \& Peterson, 2001; Syam \& Sharma, 2018) or e-commerce (Liew, Tan, \& Ismail, 2017). In his book about AI in marketing, sales and service, Gentsch (2018) recently points out the possibilities automation has for administrative, planning and creative procedures in marketing, sales and management. Like Zerfass et al. (2016) Gentsch (2018) focuses on the one hand on media and content management while on the other hand, he describes how (chat)bots and digital assistants can make communication between companies and consumers more efficient and smarter e.g., optimizing customer journeys based on algorithms and automation. Likewise, Kumar et al. (2013) and Heimbach, Kostyra, and Hinz (2015) refer to the advantages of using customer data and their metrics for automated and customized content production and distribution. However, the usage of social bots in the area of companies in general and for marketing and advertising purposes in the realm of social media or social networks is less prevalent in this field of research (cf. also Alalwan, Rana, Dwivedi, \& Algharabat, 2017; Dwivedi, Kapoor, \& Chen, 2015; Kapoor et al., 2018).

Technical communication and linguistics refer most frequently to automation and social bots in the context of sense making and sense giving of data and digital traces and how bots are programmed to interact with humans as well as leaving the same traces like humans (humanized behavior in social networks and on other online platforms) (Dourish \& Gómez Cruz, 2018; Haustein et al., 2016; Paoli, 2017; Veel, 2018). In addition, the topic of how to detect (social) bots, as well as social botnets, are in the limelight of research (Grimme, Assenmacher, \& Adam, 2017; Ross et al., 2019; Stieglitz, Mirbabaie, Ross, \& Neuberger, 2018). Furthermore, the technical aspects are well explored by Grimme, Preuss, Adam, and Trautmann (2017) with an experiment of a simple reactive Twitter Bot in which they demonstrate that "the costs for developing a simple service social bot can almost be neglected" because of the open and easy "access to the Twitter API" (p. 283). However, they pinpoint three main challenges for the development of a social bot with sophisticated human-like behavior:

1. Producing credible and 'intelligent' content, which is accepted as such by human consumers.

2. Leaving a trace of human-like meta-data in social networks. 
3. Creating an adequate (often balanced) network of friends or followers to spread information." (ibid)

The authors conclude that social bots in 2017 could easily build a "follower network, as well as posting and re-tweeting content ... without being exposed as (a) bot." (p. 286) This automatically generated network could be further used for spreading diverse content to different users in this network strategically. Using even hybrid social bot networks can lead to a "high potential of influence via social media by simulating human behavior and speech." (p. 287) However, they conclude that even with the development of deep-learning algorithms and therefore AI "human communication skills are still beyond of what algorithms can do." (ibid.) Hence, social bots can be used in different areas as proposed by Ferrara, Varol, Davis, Menczer, and Flammini (2016), but for example "the generation of intelligent and creative content" needs far more effort and resources (Grimme, Preuss et al., 2017, p. 286).

The public relations and strategic communication perspective has been dominated primarily by ideas of how research and practice might profit from big data and automation (Collister, 2015b) as well as critical perspectives with a call to take responsibility for this topic in organizational contexts (Collister, 2015a; Holtzhausen, 2016; Wiencierz \& Röttger, 2017). However, automation in general and social bots, in particular, were only discussed recently. First indications for how different organizations use automation for strategic communication purposes derived from research by Wiesenberg et al. (2017). The study from 2016 reveals that only 23.6 percent of the organizations in the sample use (semi-)automation for content distribution, 12.4 percent use it for content creation and only 7.0 percent use (semi-)automation for content adaptation. Hence, the usage of fully automated communication was not explicitly asked. They conclude that the communication profession is "lagging behind" (p. 107) and listening and messaging in the social media environment, a major task for the profession, will increasingly be done by automated programs like bots and controlled by marketers and data scientists. Communication professionals have understood the potential of big data and automation on an "abstract level", but "specific knowledge and skills, as well as a sound implementation within organizations, are often missing." (ibid., p. 108). In the same vein, Phillips (2015) argues in his book on how automation might affect strategic communication. Turning away from content focus and also taking into account how the datafication and therefore digital traces and artefacts might turn this perspective.

When considering the ethical responsibility highlighted by public relations scholars such as Holtzhausen (2016), it is necessary to consider a final review of existing literature regarding social bots in the context of ethics and the law. In a short overview, Lima Salge and Berente (2017) make clear that social bots are neither unethical nor ethical, but the way they behave are ethical or unethical. While some evil bot behavior is clearly unethical and sometimes criminal, in most cases it is "not always clear whether their undesirable activity is simply a nuisance or whether it is indeed unethical - particularly given the random nature of the logic underlying many social bots." (p. 29). For this reason, they developed a procedure to evaluate the ethics of social bot activity focusing "on the behavior of social bots with respect to law, deception, and norms" (p. 30). Therefore, they argue like Coleman (2018) and emphasize that it is not a question of automated or not, but foremost how the automated bot behaves. With his concept of bot civility Coleman (2018) proposes a concept that centers on social capital and protecting this. He concludes: "What people choose to automate, and how they choose to do so, can have very real implications to doing right or wrong, even if, prima facie, it seems merely to be a morally neutral matter of choosing one's tools." (p. 123) Hence, both the client and the developer need to take responsibility for the social bot behavior. This becomes even more important from a legal perspective when a social bot harms the reputation or dignity of an individual, entity or group or is even responsible for financial communication (Jones, 2018).

Considering the scarcity of both theoretical concepts and empirical knowledge about the perception and usage of social bots from the organizational as well as the communication and 
information management perspective, this paper takes into account the theoretical point of view previously discussed as well as the literature review above, which has stimulated the following research questions:

$R Q 1$. What are the attitudes of leading European communication professionals towards social bots?

RQ2. To what extent and how are social bots used (a) by different organizations (b) in different European regions?

\section{Method}

To answer the research questions, an online survey was conducted based on the literature review. The questions were integrated as part of the annual European Communication Monitor (2017) research among European communication professionals conducted between March and April 2017 (Zerfass et al., 2017). The section on social bots addressed the following questions (see Appendix A for operationalization, full questions and item wording): First, practitioners were asked to rate different statements based on their experience. These statements addressed the individual, the organizational, the professional as well as the social level. Secondly, respondents were asked whether their organization uses or plans to use social bots by/before the end of 2018 for strategic communication and public relations. Third, the specific (possible) usage of social bots were explored. A pre-test was held with 46 practitioners in 20 European countries. Respondents primarily corrected language and phrasing issues as the respondents were often second language English users (e.g. too complicated English word structures) and gave the suggestion to provide a short definition of social bots. Moreover, all scales have been measured for reliability tests using Cronbach's $\alpha(>0.8)$. In March 2017, a personal invitation was sent to communication professionals throughout Europe via e-mail. In total, 9,895 respondents started the survey, and 3,387 from all 50 European countries ${ }^{1}$ completed the questionnaire and could be identified as communication professionals. The study data is based on a sub-sample of 2,247 respondents from 49 European countries (see Appendix B for country and region overview of the sample) that reported being a leading communication professional: head of a communication department or agency CEO (55.2 percent, $n=1,241)$ as well as team or unit leader (44.8 percent, $n=1,006)$. Of those respondents, 54.3 percent were female $(n=1,221)$ and 45.7 percent were male $(n=1,026)$. The majority of the respondents have more than 10 years experience $(74.5$ percent, $n=1,674)$, followed by a group with $6-10$ years $(19.0$ percent, $n=428)$ and the rest were composed of a small group with less than five years experience $(6.5$ percent, $n=145)$ and work either in communication departments of listed companies (23.7 percent, $n=532$ ), private companies (23.3 percent, $n=523)$, governmental organizations $(13,7$ percent, $n=307$ ), non-profit organizations (13.5 percent, $n=303$ ) or consultancies and agencies (25.9 percent, $n=582$ ). Most of the respondents are between 40 and 49 years old (38.7 percent, $n=870)$, followed by a younger group between 30 and 39 (29.6 percent, $n=666)$ or even younger (4.1 percent, $n=92)$. One quarter is between 50 and 59 (23.6 percent, $n=531)$ or older (3.9 percent, $n=88$ ).

\section{Findings}

The following section presents the findings in accordance with the research questions. Therefore, the attitudes towards social bots from the communicators' perspective are the focus, followed by the usage of social bots and specific differences between European regions and types of organizations.

\subsection{Attitudes towards social bots (RQ1)}

${ }^{1}$ In the survey, the universe of 50 European countries is based on the official country list by the European Union (2017) and The Columbia Encyclopedia (Columbia University Press, 2000), where also regions derived from. 
One out of four respondents (39.3 percent) answer that they have followed the debate about social bots. Even though nearly half of the leading communication professionals (42.8 percent) agree that social bots offer opportunities for strategic communication, the vast majority (74.5 percent) see ethical challenges for communication professionals on the horizon when it comes to social bots and even 50.5 percent see social bots as a threat for organizations and their reputation as well as 51.6 percent a threat for societies and public debates (see Table I).

\section{- - Insert here Table I - -}

The more leading communication professionals have followed the debate on social bots, the more they see both opportunities for strategic communication $(r=0.21, p<0.01)$ and ethical challenges $(r=0.17, p<0.01)$. However, the more respondents see opportunities in social bot usage, the less they see social bots as a threat for organizations and their reputation $(r=-0.11$, $p<0.01)$ or societies and public debates $(r=-0.10, p<0.01)$. If they concentrate on ethical challenges threats to organizations and to society are the opposite way round (threat for organizations: $r=0.43, p<0.01$; threat for societies: $r=0.44, p<0.01$ ).

The perceptions regarding social bots also differ slightly between younger and older professionals. The younger professionals are, the more opportunities regarding using social bots they see $(r=-0.06, p<0.01)$. The older professionals are, the more they confirm that social bots present ethical challenges $(r=0.12, p<0.01)$, are a threat for organizations and their reputation $(r=0.14, p<0.01)$ as well as societies and public debates $(r=0.12, p<0.01)$.

Likewise the results of the Computational Propaganda Research Project (COMPROP), there are also different perceptions in different European regions (see Table II).

\section{- - Insert here Table II - -}

To conclude, on the one hand, leading European communication professionals are highly critical regarding social bots. However, every fourth professional sees opportunities arising from social bots for strategic communication and public relations. Still many see ethical challenges and threats not only for organizations and their reputation but also for the society and public debates. This critical view is much more present in Scandinavian and central European countries.

\subsection{Usage of social bots (RQ2)}

Only a few organizations already use social bots for strategic communication (see Table III). In total, only 257 leading professionals (11.5 percent) declare that their organization uses or are making plans to use social bots for strategic communication and public relations.

- - Insert here Table III - -

What are the preferred usages of social bots? Mostly they are used or are planned to be used to respond, reply or comment on posts or tweets. As presented in Table IV, the declared usage of social bots is very low in general. If organizations use social bots for strategic communication purposes, they mostly use them to respond, reply or comment on posts or tweets and to identify and follow opinion leaders.

\section{- - Insert here Table IV - -}

The leading European communication professionals report quite diverse views regarding their social bot usage. Social bots are much more used and planned to be used in Eastern and South-Eastern European countries in contrast to other European regions (see Table V). 
The usage and planned usage of social bots are primarily reported by leading communication professionals working in companies, communication consultancies and agencies in contrast to governmental as well as non-profit organizations (see Table VI).

\section{- - Insert here Table VI - -}

\section{Discussion}

The study reveals that leading European communication professionals perceive social bots as both critical and challenging and to a lesser extent as an opportunity for strategic communication and public relations. This more critical perception might be strongly influenced by negative news media coverage where social bots have been portrayed adversely as computational propaganda in many Western and Central European countries. However, it is also a reflection of the ongoing scientific discourse presented in the literature review. Moreover, communications professionals see ethical challenges and threats for both societies and for organizations and their reputation. Referring to the literature review and especially to the ethical concerns regarding social bots, Coleman (2018) as well as Lima Salge and Berente (2017) particularly point out that the ethical question is not regarding using or not using automation and especially social bots, but regarding ownership and agency as well as purpose of the specific social context in which this automated communication is used. That might be also an explanation for the much higher use of social bots in Eastern and South-Eastern European counties where the perceptions regarding social bots seem to be less critical and sceptical (see also Woolley \& Howard, 2018).

The results also reflect the uncertainties of many leading communication professionals from different organizations regarding the current usage and potential usages of social bots and other kinds of automation in social media and social networks in general. In their literature review on social media, Kapoor et al. (2018) highlight a growing number of research studies in the "dysfunctional consequences of social media adoption, such as - addiction, stress, information overload, and others." (p. 544) Bearing in mind the literature review focused on the usage of social bots in the realm of elections as well as the potential social bots offer for all kinds of organizations, the question needs to be raised about to what extent social bots play a part in contributing to such dysfunctional consequences such as information overload. Because there are no specific laws regarding either the usage of automated communication in general or social bots in particular (Howard et al., 2018; Jones, 2018). This suggests a need for further discussions regarding transparency of datafication in all kinds of communication activities, be it the identification of "relevant word-of-mouth in social media" (Vermeer, Araujo, Bernritter, $\&$ van Noort, 2019) or messaging via bots - that leads to the discussion of the anthropomorphism of social bots (Araujo, 2018). From the technical side, the goal to develop social bots with human-like behavior seems more and more promising. However, many leading communication professionals are reluctant regarding the implementation of these innovations.

In contrast, ethical challenges and the possible threats of social bots are not a barrier for others using them for strategic communication. 4.0 percent $(n=89)$ already used social bots in 2017 and 7.5 percent $(n=168)$ declare they will use social bots by/before the end of 2018 . These organizations are primarily companies as well as consultancies and agencies that use or plan to use social bots. This result indicates that innovation and programming of social bots for strategic communication purposes still needs many resources. Something that is quite rare in non-profit and governmental organizations. However, governmental organizations rely on data and a lot of communication is standardized. For example, Androutsopoulou, Karacapilidis, Loukis, and Charalabidis (2019) demonstrate how three Greek government agencies have been implementing AI-guided chatbots to develop a new digital channel of communication between 
citizens and government. Another example is presented by Singh et al. (2019) that suggests how the Indian government could benefit from efficient monitoring and controlling of governmental policies through public involvement and could even save resources by using transparent bots (see also Bhimani, Mention, \& Barlatier, 2019; Lee \& VanDyke, 2015; Zerfass \& Schramm, 2014). In addition, non-profits could benefit from using social bots e.g., in donor communications or news feeds on their social media channels. This leads to the hypothesis that communication professionals working in the non-profit or governmental sector are less involved in bringing up digital innovation and ideas, as designing and building bots today becomes less expensive and complex (Grimme, Preuss et al., 2017; Rozga, 2018).

The study also highlights issues around the division of labor with communication leaders having responsibility for a critical area of day to day organizational communication. Using automated insights engines for listening or social bots for automated communication based on algorithms is often perceived as a magical 'black box' for leading European communication professionals (see also Collister, 2015a, Wiesenberg et al., 2017). The lack of knowledge about the workings and content of these 'black boxes' reflects a potential strategic ignorance or competence gap for these communication leaders and does bring unintended consequences. Moreover, the results highlight a generation gap between the younger and older generation. However, as Vokic and Vidovic (2015) brought up in another context, this might be a digital divide between the ones that developed their technical skills and knowledge and the ones that did not. Concomitantly, this indicates that communication professionals working as leaders in their organizations need to be trained and train themselves, especially in these areas. Moreover, younger professionals need further ethical guidance in times of deep mediatization by superiors as well as professional associations. Therefore, scholars, professionals and their associations must develop ethical guidelines that help the profession to overcome the ethical challenges facing developments such as social bots in order to understand and integrate the use of such new technologies.

\subsection{Theoretical contributions}

The results of the research presented above demonstrate that communication professionals in Europe are aware of the possibilities that automation and especially social bots can have for their work in strategic communication and information management. Bearing in mind the results of Wiesenberg, Zerfass, and Moreno (2017) as well as the concept of strategic mediatization (Zerfass et al., 2016) in this paper we propose the concept of deep strategic mediatization. Referring to results from these studies as well as the different scenarios automation and especially social bots can be used for in communication and information management (Ferrara et al., 2016; Gorwa \& Guilbeault, 2018; Grimme, Preuss et al., 2017; Ross et al., 2019; Stieglitz et al., 2017) and reflecting the results presented in this study, we found support for our proposed concept on deep strategic mediatization and would like to elaborate the concept further.

Communication and information management are based on analytics, planning and executing programmes and campaigns and then ultimately evaluating their impact and effects. The concept of deep strategic mediatization presents new ways for modelling data and algorithms within these stages and potentially opens up the enigmatic black box (Collister, 2015a. Wiesenberg et al., 2017) to understand strategic communication more fully. For example, in the stage of analytics, there are a growing number of software solutions in the market that can be used for all kind of social media and further communication, monitoring, measurement and evaluative analytics. By building on these sometimes expensive software solutions, communication professionals can make sense of their digital environments and start planning their strategies and campaigns with greater understanding and insights. Practitioners trust this software without necessarily understanding or knowing much about these algorithms. The same is true for planning and executing when communication professionals use software or social bots to 
develop communication programmes or campaigns and subsequently disseminate the communication content to specific and targeted stakeholders.

\subsection{Practical implications}

Following the theoretical implications, communication and information managers need to bear in mind that the usage of such fully or semi-automated tools as well as data traces etc. have direct and indirect consequences for their own organization (reputational risk), for individuals (data protection and human dignity) and for society (fully functioning public sphere). The results also indicate that there are significant differences between European regions regarding the perception of social bot usage. These all present practical implications for individual communication specialists, their departments and organizations more broadly. The influences and impact also extends to the professional associations and representative institutes advising, guiding and developing future communication leaders and managers. A linked practical implication, reinforced by this study's findings, relates to the frequently cited contemporary business problem of information overload as a contributor to Kapoor et al.'s (2018) “dysfunctional consequences of social media adoption".

Some of the capabilities and competency gaps the research highlights are in terms of ethics and legal understanding. In addition there is a clear need to advance a more detailed appreciation of the technology itself, irrespective of age, region or demographic profile. Therefore there is an overall and previously discussed related requirement for professional and practical training and develop on the technical and practical understanding of social bots and on the integration of codices which encapsulate ethical guidance and guidelines which could all be developed by representative communication management industry bodies and associations.

In the context of communication practice its apparent only a few organizations - 12 per cent of the study sample - use social bots in their strategic communication. With such a small proportion already engaging with or planning to use social bots in their communication activities, there are two practical implications. Firstly that organizations integrating and utilizing social bots in their strategic communication are leading their peers in the field. Secondly these organizations, according to the comparative excellence framework (CEF) for communication management (Zerfass et al. 2014) and the communication excellence model (Tench et al. 2017), are demonstrating the attributes of high performing communication departments. These departments and individuals are leading the field and differentiating themselves and their organizations.

To develop the competence and capabilities of the next generation of communication management specialists the paper is suggesting direct practical solutions to fill the gap. By addressing these knowledge and practice deficiencies, organizations will be better able to maximise their engagement with and practical use of social bots. Similarly, by more deeply appreciating social bots and their capabilities and deficiencies it may be possible to ameliorate against some of the legal and ethical challenges of social bot usage inside and outside the organizational setting that already exist and are some of the potential threats in the future.

\subsection{Limitations and future research perspectives}

This research has some limitations to be considered, especially for deep strategic mediatization. The most obvious limitation is the sample itself. As the universe of communication professionals in Europe is unknown, these quantitative data present only a first insight into the status quo of the perception and usage of social bots in Europe. Also, the response rate from Eastern European communication professionals was lower than other regions so that conclusions regarding 
the appearance and perceptions regarding social bots need further investigations, especially in this region. As the results from the different European regions indicate, the understanding of social bots might be different as the knowledge of the English language varies substantially across Europe and therefore definitions might be open to different interpretations like the reference to the US presidential campaign in the introduction text (see Appendix A). This might also have influenced the negative connotations to computational propaganda. To make this clearer after the pretest, we added our definition to the introduction text, but stayed with the reference to the US presidential campaign provides a contemporary example, as this was not mentioned as problematic in the pretest. However, the critical position of the majority of communication professionals in the survey results gives at least some indication that this might the case. Therefore, future research should take not only one example for the introduction that is strongly negatively connoted but also two or three that describe the phenomenon in other contexts.

The implications for future research agendas stretch from organizational communication practice to the impact of deep strategic mediatization. This research focused on how communication professionals perceive social bots as well as to what extent organizations use social bots. Referring to the perceived threats regarding social bots reported above, it needs further research in how communication departments are prepared if social bots manipulate and spread specific meaning creations. Research for communication professionals is also required in understanding automation beyond social bots and focus more on digital artefacts and acts and the consequences they have for societies, organizations and professionals alike. This extends to perhaps questioning the strategic ignorance of a community of practitioners at the more senior level who from the data in this paper demonstrate a lack of awareness and understanding of technology and its application. This may lead to practice based questions of how labor division in communication management and the implications for managers who own and are responsible for organizational communication but demonstrate ignorance of those tools they give guidance on and supposedly control. Greater understanding of this competence gap is a further area for enquiry hand in hand with the question of why some leading communication professionals are in favor and some are against the usage of social bots. Indications from the study above delivered some assumptions like the specific regions with its social values, age and type of organization. As the questions have been part of a larger study, further advanced analyses have not been possible. However, the descriptive results demonstrate a first view into this important topic of social bot perception and usage in the context of the concept of deep strategic mediatization.

The results presented above, therefore, offer diverse starting points for further research in the perception and usage of digital traces and automation in strategic communication. The low active usage of social bots in 2017 needs further investigation in the future. Because this study was answered anonymously, it is also unclear if professionals are working for the same organization. As this research only focuses on the phenomenon of social bots in social networks, it needs further insights into how strategic communication and public relations professionals perceive and use data to make sense out of digital traces from different stakeholders and how they use these data to guide, influence or manipulate stakeholders to reach the organization's goal(s). This will lead us as a scientific community to the question of where manipulations of such digital traces start and co-creation of meaning ends. This debate is not new, but has never been brought up in the realm of strategic communication in times of deep mediatization or as it is proposed in this article and an area for future research enquiry, deep strategic mediatization.

With the advent of AI in communication and information management as well as marketing research (Duan, Edwards, \& Dwivedi, 2019; Dwivedi et al., 2019; Galloway \& Swiatek, 2018; Kose \& Sert, 2017; Olson \& Levy, 2018; Petrucci, 2018; Wirth, 2018) it becomes crystal clear that the usage of social bots, as well as its detection, opens up new streams of research where data and therefore digital artefacts and acts need further investigations including developing understanding of its downsides and limits. Once again, there are potential opportunities 
and risks for the individual, organizational as well as at the broader, societal level which need to be taken into consideration. For example, in their multidisciplinary literature review, Dwivedi and colleagues (2019) wrap up diverse themes of AI research as well as the challenges for AI that this research has also broached: AI is primarily used for decision making for what is the core of modern business as well as for communication and information management. To run analytics is one point; to decide what to do has been the domain for humans so far but becomes also more and more the domain of artificial intelligence (if not the main domain). The application domain, that explicitly covers the usage of social bots and other kinds of bots, offers great potential in the realm beyond text. With the advent of intelligent voice and audio systems like Alexa, this needs further investigation on how these applications are really based on artificial intelligence and what the limits of such applications are. Moreover, the challenges, as well as ethical, legal and political consequences, need to be taken into consideration (ibid.). To conclude, there are diverse streams of new research agendas opened up here that are becoming part of our daily lives as well as our research experience far faster than might have been expected.

\section{Conclusions}

This paper explores the knowledge and usage of social bots by organizational leaders in an era when trust is declining in many institutions and professions. More broadly in this context, the media itself has been highlighted as experiencing a loss of trust (European Commission, 2018). Studies explored in the review of the literature underline this point when focused on the specifics of disinformation and propaganda campaigning on the social web. The discussion has integrated the theoretical concepts and empirical knowledge gained from this study which explored the perceptions and practical usage of social bots by organizations as well as integrating the individual's communication and information management perspective. From previous studies and debates together with the results in this study we have found support for the concept of deep strategic mediatization. This is founded on the discussions about deep mediatization and the specifics in the communication of strategic mediatization. By discussing automation (developing content with data and algorithms) and more specifically the use and potential application of social bots to produce or distribute content for strategic communication and information purposes, this paper challenges the disinformation bias of social bots and instead introduces the concept of deep strategic mediatization. The paper has presented empirical evidence on the status quo of social bot usage and therefore some first indications on the deep strategic mediatization concept. The significant changes in times of deep mediatization and the results presented in this research indicate that social bots and bot communication are not simply a modern interpretation of media manipulation and propaganda. If one only highlights the issue of computational propaganda this might appear as a plausible explanation, particularly as most communication professionals perceive social bots as a threat for organizations and societies alike. However, as demonstrated above, social bots are only one form of automated communication. Even though the empirical results demonstrate that only a small number of organizations already use or plan to use social bots, this makes fundamentally clear that we are opening a new chapter in strategic communication by taking digital traces into account. This paper argues that one perspective of this is that we are witnessing an evolution that could be interpreted as a process of moving towards deep strategic mediatization.

\section{References}

Alalwan, A. A., Rana, N. P., Dwivedi, Y. K., \& Algharabat, R. (2017). Social media in marketing: A review and analysis of the existing literature. Telematics and Informatics, 34(7), 1177-1190. https://doi.org/10.1016/j.tele.2017.05.008 
Anderson, C. W. (2017). Beyond the Article: Frontiers of Editorial and Commercial Innovation. Digital News Project 2017. Oxford: Reuters Institute for the Study of JournalismUniversity of Oxford. Retrieved from https://reutersinstitute.politics.ox.ac.uk/sites/default/files/2017-10/Beyond $\% 20$ the $\% 20$ Article $\% 20-\% 20$ Frontiers $\% 20$ of $\% 20$ Editorial\%20and\%20Commercial\%20Innovation.pdf

Androutsopoulou, A., Karacapilidis, N., Loukis, E., \& Charalabidis, Y. (2019). Transforming the communication between citizens and government through AI-guided chatbots. Government Information Quarterly, 36(2), 358-367. https://doi.org/10.1016/j.giq.2018.10.001

Appel, G., Grewal, L., Hadi, R., \& Stephen, A. T. (2019). The future of social media in marketing. Journal of the Academy of Marketing Science. Advance online publication. https://doi.org/10.1007/s11747-019-00695-1

Araujo, T. (2018). Living up to the chatbot hype: The influence of anthropomorphic design cues and communicative agency framing on conversational agent and company perceptions. Computers in Human Behavior, 85, 183-189. https://doi.org/10.1016/j.chb.2018.03.051

Bessi, A., \& Ferrara, E. (2016). Social bots distort the 2016 U.S. Presidential election online discussion. First Monday, 21(11). https://doi.org/10.5210/fm.v21i11.7090

Bhimani, H., Mention, A.-L., \& Barlatier, P.-J. (2019). Social media and innovation: A systematic literature review and future research directions. Technological Forecasting and Social Change, 144, 251-269. https://doi.org/10.1016/j.techfore.2018.10.007

Bolsover, G., \& Howard, P. N. (2017). Computational Propaganda and Political Big Data: Moving Toward a More Critical Research Agenda. Big data, 5(4), 273-276. https://doi.org/10.1089/big.2017.29024.cpr

Bolsover, G., \& Howard, P. N. (2018). Chinese computational propaganda: Automation, algorithms and the manipulation of information about Chinese politics on Twitter and Weibo. Information, Communication \& Society, 27(2), 1-18. https://doi.org/10.1080/1369118X.2018.1476576

Bradshaw, P. (2018). The online journalism handbook: Skills to survive and thrive in the digital age (2nd ed.). London: Routledge.

Coleman, M. C. (2018). Bots, Social Capital, and the Need for Civility. Journal of Media Ethics, 33(3), 120-132. https://doi.org/10.1080/23736992.2018.1476149

Collister, S. (2015a). Algorithmic Public Relations: Materiality, Technology and Power in a Post-Hegemonic World. In D. McKie, J. L'Etang, J. Xifra, \& N. Snow (Eds.), The Routledge handbook of critical public relations (pp. 360-371). London: Routledge.

Collister, S. (2015b). Analysing Algorithms in Public Relations Research: Contexts, Challenges and Innovative Methodologies. EUPRERA 2015 Annual Conference, Oslo, Norway.

Columbia University Press (2000). The Columbia Encyclopedia. Retrieved from https://www.encyclopedia.com/reference/encyclopedias-almanacs-transcripts-andmaps/europe

Couldry, N., \& Hepp, A. (2017). The Mediated Construction of Reality. New York, NY: John Wiley \& Sons.

Dourish, P., \& Gómez Cruz, E. (2018). Datafication and data fiction: Narrating data and narrating with data. Big Data \& Society, 5(2), 1-10. https://doi.org/10.1177/2053951718784083

Duan, Y., Edwards, J. S., \& Dwivedi, Y. K. (2019). Artificial intelligence for decision making in the era of Big Data - evolution, challenges and research agenda. International Journal 
of Information Management, 48(October), 63-71. https://doi.org/10.1016/j.ijinfomgt.2019.01.021

Dwivedi, Y. K., Hughes, L., Ismagilova, E., Aarts, G., Coombs, C., Crick, T., . . Williams, M. D. (2019). Artificial Intelligence (AI): Multidisciplinary perspectives on emerging challenges, opportunities, and agenda for research, practice and policy. International Journal of Information Management. Advance online publication. https://doi.org/10.1016/j.ijinfomgt.2019.08.002

Dwivedi, Y. K., Kapoor, K. K., \& Chen, H. (2015). Social media marketing and advertising. The Marketing Review, 15(3), 289-309. https://doi.org/10.1362/146934715X14441363377999

European Commission (2018): Standard Eurobarometer 90 - Autumn 2018: Media use in the European Union (Report, November 2018). Brussels. Retrieved fromhttp://ec.europa.eu/commfrontoffice/publicopinion/index.cfm/ResultDoc/download/Docu$\underline{\text { mentKy/86433 }}$

European Union (2017). The 28 member countries of the EU. Retrieved from https://europa.eu/european-union/about-eu/countries_en

Ferrara, E. (2017). Disinformation and social bot operations in the run up to the 2017 French presidential election. First Monday, 22(8). https://doi.org/10.5210/fm.v22i8.8005

Ferrara, E., Varol, O., Davis, C., Menczer, F., \& Flammini, A. (2016). The rise of social bots. Communications of the ACM, 59(7), 96-104. https://doi.org/10.1145/2818717

Fürst, S., \& Oehmer, F. (2018). „Twitter-Armies“, „Earned Media“ und „Big Crowds“ im US-Wahlkampf 2016 [,,Twitter-Armies“, „Earned Media“ and „Big Crowds“ in the US election 2016]. In M. Oswald \& M. Johann (Eds.), Strategische Politische Kommunikation im digitalen Wandel [Strategic political communication in digital changes] (pp. 35-61). Wiesbaden, Germany: Springer VS. https://doi.org/10.1007/978-3-658-20860-8_3

Galloway, C., \& Swiatek, L. (2018). Public relations and artificial intelligence: It's not (just) about robots. Public Relations Review, 44(5), 734-740. https://doi.org/10.1016/j.pubrev.2018.10.008

Gentsch, P. (2018). AI in Marketing, Sales and Service: How Marketers without a Data Science Degree can use AI, Big Data and Bots. Cham: Palgrave Macmillan.

Gorwa, R., \& Guilbeault, D. (2018). Unpacking the Social Media Bot: A Typology to Guide Research and Policy. Policy \& Internet, 40(3), 420. https://doi.org/10.1002/poi3.184

Grimme, C., Assenmacher, D., \& Adam, L. (2017). Changing Perspectives: Is It Sufficient to Detect Social Bots? In G. Meiselwitz (Ed.), Social Computing and Social Media. Human Behavior (pp. 445-461). Cham: Springer International.

Grimme, C., Preuss, M., Adam, L., \& Trautmann, H. (2017). Social Bots: Human-Like by Means of Human Control? Big Data, 5(4), 279-293. https://doi.org/10.1089/big.2017.0044

Haustein, S., Bowman, T. D., Holmberg, K., Tsou, A., Sugimoto, C. R., \& Larivière, V. (2016). Tweets as impact indicators: Examining the implications of automated "bot" accounts on Twitter. Journal of the Association for Information Science and Technology, 67(1), 232-238. https://doi.org/10.1002/asi.23456

Heimbach, I., Kostyra, D. S., \& Hinz, O. (2015). Marketing Automation. Business \& Information Systems Engineering, 57(2), 129-133. https://doi.org/10.1007/s12599-015-0370-8

Hepp, A., Breiter, A., \& Hasebrink, U. (2018). Rethinking Transforming Communications: An Introduction. In A. Hepp, A. Breiter, \& U. Hasebrink (Eds.), Communicative Figurations: Transforming Communications in Times of Deep Mediatization (pp. 3-13). Cham: Palgrave Macmillan. 
Hersh, E. D., \& Schaffner, B. F. (2013). Targeted Campaign Appeals and the Value of Ambiguity. The Journal of Politics, 75(2), 520-534.

https://doi.org/10.1017/S0022381613000182

Holtzhausen, D. R. (2016). Datafication: Threat or opportunity for communication in the public sphere? Journal of Communication Management, 20(1), 21-36. https://doi.org/10.1108/JCOM-12-2014-0082

Holtzhausen, D. R., \& Zerfass, A. (2015). Strategic Communication: Opportunities and Challenges of the Research Area. In D. R. Holtzhausen \& A. Zerfass (Eds.), Routledge handbooks. The Routledge handbook of strategic communication (pp. 3-17). New York, NY: Routledge.

Howard, P. N., Woolley, S. C., \& Calo, R. (2018). Algorithms, bots, and political communication in the US 2016 election: The challenge of automated political communication for election law and administration. Journal of Information Technology \& Politics, 15(2), 8193. https://doi.org/10.1080/19331681.2018.1448735

Ihlen, Ø., \& Pallas, J. (2014). 18. Mediatization of corporations. In K. Lundby (Ed.), Mediatization of Communication. Berlin: de Gruyter. https://doi.org/10.1515/9783110272215.423

Jones, M. L. (2018). Silencing Bad Bots: Global, Legal and Political Questions for Mean Machine Communication. Communication Law and Policy, 23(2), 159-195. https://doi.org/10.1080/10811680.2018.1430418

Kapoor, K. K., \& Dwivedi, Y. K. (2015). Metamorphosis of Indian electoral campaigns: Modi's social media experiment. International Journal of Indian Culture and Business Management, 11(4), 496-516. https://doi.org/10.1504/IJICBM.2015.072430

Kapoor, K. K., Tamilmani, K., Rana, N. P., Patil, P., Dwivedi, Y. K., \& Nerur, S. (2018). Advances in Social Media Research: Past, Present and Future. Information Systems Frontiers, 20(3), 531-558. https://doi.org/10.1007/s10796-017-9810-y

Karanasios, S., Thakker, D., Lau, L., Allen, D., Dimitrova, V., \& Norman, A. (2013). Making sense of digital traces: An activity theory driven ontological approach. Journal of the American Society for Information Science and Technology, 64(12), 2452-2467. https://doi.org/10.1002/asi.22935

Kose, U., \& Sert, S. (2017). Improving content marketing processes with the approaches by artificial intelligence. Ecoforum Journal, 6(1). Retrieved from http://arxiv.org/pdf/1704.02114v1

Kumar, V., Chattaraman, V., Neghina, C., Skiera, B., Aksoy, L., Buoye, A., \& Henseler, J. (2013). Data-driven services marketing in a connected world. Journal of Service Management, 24(3), 330-352. https://doi.org/10.1108/09564231311327021

Larsson, A. O., \& Hallvard, M. (2015). Bots or journalists?: News sharing on Twitter. Communications, 40(3). https://doi.org/10.1515/commun-2015-0014

Lee, N. M., \& VanDyke, M. S. (2015). Set It and Forget It. Science Communication, 37(4), 533-541. https://doi.org/10.1177/1075547015588600

Liew, T. W., Tan, S.-M., \& Ismail, H. (2017). Exploring the effects of a non-interactive talking avatar on social presence, credibility, trust, and patronage intention in an e-commerce website. Human-centric Computing and Information Sciences, 7(1), 7. https://doi.org/10.1186/s13673-017-0123-4

Lima Salge, C. A. de, \& Berente, N. (2017). Is that social bot behaving unethically? Communications of the ACM, 60(9), 29-31. https://doi.org/10.1145/3126492

Lokot, T., \& Diakopoulos, N. (2016). News Bots. Digital Journalism, 4(6), 682-699. https://doi.org/10.1080/21670811.2015.1081822 
Malhotra, N. K., \& Peterson, M. (2001). Marketing research in the new millennium: Emerging issues and trends. Marketing Intelligence \& Planning, 19(4), 216-232. https://doi.org/10.1108/EUM0000000005560

Nickerson, D. W., \& Rogers, T. (2014). Political Campaigns and Big Data. Journal of Economic Perspectives, 28(2), 51-74. https://doi.org/10.1257/jep.28.2.51

Olson, C., \& Levy, J. (2018). Transforming marketing with artificial intelligence. Applied Marketing Analytics, 3(4), 291-297.

Oxford Internet Institute (2018). Computational Propaganda Research Project (COMPROP). Retrieved from http://comprop.oii.ox.ac.uk/

Paoli, S. de (2017). Not All the Bots Are Created Equal: The Ordering Turing Test for the Labeling of Bots in MMORPGs. Social Media + Society, 3(4), 1-13. https://doi.org/10.1177/2056305117741851

Petrucci, A. (2018). How Artificial Intelligence Will Impact Corporate Communications. Retrieved from https://www.forbes.com/sites/forbescommunicationscouncil/2018/04/20/howartificial-intelligence-will-impact-corporate-communications/\#735395ee1dc6

Phillips, D. (2015). The Automation of Public Relations: A perspective on the development of automation affecting Public Relations: BLURB.

Poloski Vokic, N., \& Vidovic, M. (2015). Managing internal digital publics: What matters is digital age not digital nativity. Public Relations Review, 41(2), 232-241.

https://doi.org/10.1016/j.pubrev.2014.12.004

Ross, B., Pilz, L., Cabrera, B., Brachten, F., Neubaum, G., \& Stieglitz, S. (2019). Are social bots a real threat? An agent-based model of the spiral of silence to analyse the impact of manipulative actors in social networks. European Journal of Information Systems, 25(3), 1-19. https://doi.org/10.1080/0960085X.2018.1560920

Rozga, S. (Ed.). (2018). Practical Bot Development: Designing and Building Bots with Node.js and Microsoft Bot Framework. Berkeley, CA: Apress.

Singh, P., Dwivedi, Y. K., Kahlon, K. S., Sawhney, R. S., Alalwan, A. A., \& Rana, N. P. (2019). Smart Monitoring and Controlling of Government Policies Using Social Media and Cloud Computing. Information Systems Frontiers, 1-23. https://doi.org/10.1007/s10796019-09916-y

Stella, M., Ferrara, E., \& Domenico, M. de (2018). Bots increase exposure to negative and inflammatory content in online social systems. Proceedings of the National Academy of Sciences of the United States of America, 115(49), 12435-12440.

https://doi.org/10.1073/pnas.1803470115

Stieglitz, S., Brachten, F., Berthelé, D., Schlaus, M., Venetopoulou, C., \& Veutgen, D. (2017). Do Social Bots (Still) Act Different to Humans? - Comparing Metrics of Social Bots with Those of Humans. In G. Meiselwitz (Ed.), Social Computing and Social Media. Human Behavior (pp. 379-395). Cham: Springer International.

Stieglitz, S., Mirbabaie, M., Ross, B., \& Neuberger, C. (2018). Social media analytics - Challenges in topic discovery, data collection, and data preparation. International Journal of Information Management, 39, 156-168. https://doi.org/10.1016/j.ijinfomgt.2017.12.002

Syam, N., \& Sharma, A. (2018). Waiting for a sales renaissance in the fourth industrial revolution: Machine learning and artificial intelligence in sales research and practice. Industrial Marketing Management, 69, 135-146. https://doi.org/10.1016/j.indmarman.2017.12.019

Tench, R., Verčič, D., Zerfass, A., Moreno, A., \& Verhoeven, P. (2017). Communication Excellence. How to develop, manage and lead exceptional communications. Cham: Palgrave Macmillan. 
Turing, A. (1950). Computing Machinery and Intelligence. Mind, 59(October), 433-466.

Van Dijck, J. (2014). Datafication, dataism and dataveillance: Big Data between scientific paradigm and ideology. Surveillance \& Society, 12(2), 197-208.

Veel, K. (2018). Make data sing: The automation of storytelling. Big Data \& Society, 5(1), 18. https://doi.org/10.1177/2053951718756686

Vermeer, S. A.M., Araujo, T., Bernritter, S. F., \& van Noort, G. (2019). Seeing the wood for the trees: How machine learning can help firms in identifying relevant electronic word-ofmouth in social media. International Journal of Research in Marketing. Advance online publication. https://doi.org/10.1016/j.ijresmar.2019.01.010

Wiencierz, C., \& Röttger, U. (2017). The use of big data in corporate communication. Corporate Communications: an International Journal, 22(3), 258-272. https://doi.org/10.1108/CCIJ-02-2016-0015

Wiesenberg, M., Zerfass, A., \& Moreno, A. (2017). Big Data and Automation in Strategic Communication. International Journal of Strategic Communication, 11(2), 95-114. https://doi.org/10.1080/1553118X.2017.1285770

Wirth, N. (2018). Hello marketing, what can artificial intelligence help you with? International Journal of Market Research, 60(5), 435-438. https://doi.org/10.1177/1470785318776841

Woolley, S. C. (2016). Automating power: Social bot interference in global politics. First Monday, 21(4). https://doi.org/10.5210/fm.v21i4.6161

Woolley, S. C., \& Howard, P. N. (2016a). Political Communication, Computational Propaganda, and Autonomous Agents: Introduction. International Journal of Communication, 10 .

Woolley, S. C., \& Howard, P. N. (2016b). Social Media, Revolution, and the Rise of the Political Bot. In P. Robinson, P. M. Seib, \& R. Fröhlich (Eds.), Routledge handbook of media, conflict and security (pp. 282-292). New York, NY: Routledge.

Woolley, S. C., \& Howard, P. N. (Eds.). (2018). Oxford studies in digital politics. Computational propaganda: Political parties, politicians, and political manipulation on social media. New York, NY: Oxford University Press.

Xu, X.-Z. M., \& Roland Kaye, G. (1997). Beyond automation and control: Manufacturing information systems from a strategic perspective. International Journal of Information Management, 17(6), 437-449. https://doi.org/10.1016/S0268-4012(97)00026-1

Zerfass, A., Moreno, Á., Tench, R., Verčič, D., \& Verhoeven, P. (2017). European Communication Monitor 2017. Brussels, Berlin: EACD - European Association of Communication Directors; EUPRERA - European Public Relations Education and Research Association; Quadriga Media.

Zerfass, A., \& Schramm, D. M. (2014). Social Media Newsrooms in public relations: A conceptual framework and corporate practices in three countries. Public Relations Review, 40(1), 79-91. https://doi.org/10.1016/j.pubrev.2013.12.003

Zerfass, A., Tench, R., Verčič, D., Verhoeven, P., \& Moreno, A. (2014). European Communication Monitor 2014. Excellence in strategic communication - Key issues, leadership, gender and mobile media. Results of a survey in 42 countries. Brussels. Belgium: EACD/EUPRERA, Helios Media.

Zerfass, A., Verčič, D., Verhoeven, P., Moreno, A., \& Tench, R., (2015). European Communication Monitor 2015. Creating communication value through listening, messaging and measurement. Results of a survey in 41 countries. Brussels. Belgium: EACD/EUPRERA, Helios Media. 
Zerfass, A., Verčič, D., \& Wiesenberg, M. (2016). The dawn of a new golden age for media relations? Public Relations Review, 42(4), 499-508.

https://doi.org/10.1016/j.pubrev.2016.03.005 


\section{Appendix A}

\section{Question 1:}

Nowadays many social media accounts are run by automated software applications, so-called "social bots". They are communicating much faster and more intensively than humans which has stimulated a debate about this phenomenon, e.g. during the recent US presidential campaign and among strategic communication experts. Please rate these statements based on your experience:

Item 1: I have followed the debate about social bots

Item 2: Social bots offer opportunities for strategic communication

Item 3: Social bots present ethical challenges for communication professionals

Item 4: Social bots are a threat for organisations and their reputation

Item 5: Social bots are a threat for societies and public debates

Five-point Likert scale ranging from 1 = "Strongly disagree" to 5 = "Strongly agree".

Optional item: I don't know at all (skip section).

\section{Background/Operationalization:}

Definition of social bots: A social bot is a computer algorithm that automatically produces content and interacts with humans mainly on social media, trying to emulate and possibly alter their behavior.

Most of the debate on social bots is shaped negatively (computational propaganda). However, they offer also many possibilities for strategic communication and information management (see chapter 2.2). The first item was stated to identify how many communication professionals in different European countries have followed this debate (as it was broadly discussed in public media). Moreover, the literature review revealed opportunities for social bot usage and threats on the meso and macro level as well as ethical challenges.

\section{Question 2:}

Does your organisation or agency use social bots for strategic communication and public relations?

Items (only choose one):

1. We use social bots

2. We are making plans to use social bots by/before the end of 2018

3. We do not use social bots

4. I don't know

\section{Question 3 a (if already use social bots):}

How does your department or agency use social bots? (multiple answers possible)

We use social bots to automatically...

1. identify and follow users on social networks

2. like, forward or retweet posts/tweets

3. respond, reply or comment on posts/tweets

4. create content and post/tweet it on social networks

Extra item (if not sure): We use social bots, but I don't know exactly how. 
Question $3 b$ (if planned to use social bots):

How does your department or agency plan to use social bots? (multiple answers possible)

We are making plans to use social bots to automatically...

1. identify and follow users on social networks

2. like, forward or retweet posts/tweets

3. respond, reply or comment on posts/tweets

4. create content and post/tweet it on social networks

Extra item (if not sure): We are making plans to use social bots, but I don't know exactly how.

\section{Background/Operationalization:}

The items represent different intensities of communicating on social media based on bots based on Bessi and Ferrara (2016):

- $\quad$ Item 1 stands for monitoring social media communication without interfering, i.e. identifying users and following them but not communicating actively.

- Item 2 reflects the simplest form of contributing to the debate by supporting a statement/message or distributing it (without adding new content to the debate).

- Item 3 stands for entering a debate (reactively) by answering, commenting etc., i.e. jumping on the bandwagon using agenda surfing.

- $\quad$ Item 4 stands for opening a discussion (actively) by posting something on one's own or other social media accounts (new content indexed in search engines containing certain topics, standpoints etc.).

\section{Appendix B}

TABLE APPENDIX B

European countries and regions in the sample with number of respondents

\begin{tabular}{|c|c|c|c|c|c|}
\hline Country/Region & Mean Age & Median & Female $(\%)$ & Frequency & Percent \\
\hline Denmark & 46.24 & 46 & 29.3 & 41 & 1.8 \\
\hline Finland & 46.65 & 46 & 77.3 & 88 & 3.9 \\
\hline Iceland & 56.00 & 56 & 0.0 & 1 & 0.0 \\
\hline Norway & 46.30 & 44 & 44.3 & 61 & 2.7 \\
\hline Sweden & 46.81 & 47 & 52.5 & 80 & 3.6 \\
\hline Scandinavia & 46.59 & 46 & 55.0 & 271 & 12.1 \\
\hline Ireland & 44.85 & 45 & 59.2 & 71 & 3.2 \\
\hline United Kingdom & 43.01 & 42 & 52.1 & 290 & 12.9 \\
\hline British Isles & 43.37 & 43 & 53.5 & 361 & 16.1 \\
\hline Belgium & 43.43 & 43 & 59.0 & 144 & 6.4 \\
\hline France & 45.04 & 45 & 64.8 & 91 & 4.0 \\
\hline Luxembourg & 44.00 & 44 & 50.0 & 14 & 0.6 \\
\hline Monaco & 50.00 & 50 & 100.0 & 2 & 0.1 \\
\hline Netherlands & 46.78 & 47 & 48.3 & 116 & 5.2 \\
\hline Western Europe & 44.95 & 45 & 56.9 & 367 & 16.3 \\
\hline Austria & 43.98 & 45 & 71.4 & 49 & 2.2 \\
\hline Czech Republic & 38.58 & 38 & 38.0 & 71 & 3.2 \\
\hline Germany & 46.41 & 47 & 39.1 & 179 & 8.0 \\
\hline Hungary & 39.68 & 40 & 63.2 & 19 & 0.8 \\
\hline Liechtenstein & 49.00 & 49 & 0.0 & 1 & 0.0 \\
\hline Poland & 40.33 & 40 & 48.8 & 43 & 1.9 \\
\hline Slovakia & 41.00 & 40 & 66.7 & 6 & 0.3 \\
\hline Switzerland & 45.77 & 46 & 51.4 & 146 & 6.5 \\
\hline Central Europe & 44.10 & 45 & 47.5 & 514 & 22.9 \\
\hline
\end{tabular}




\begin{tabular}{|c|c|c|c|c|c|}
\hline Andorra & 57.00 & 57 & 100.0 & 1 & 0.0 \\
\hline Italy & 46.28 & 46 & 49.6 & 135 & 6.0 \\
\hline Malta & 48.50 & 49 & 33.3 & 6 & 0.3 \\
\hline Portugal & 43.83 & 43 & 47.5 & 40 & 1.8 \\
\hline San Marino & 34.00 & 34 & 0.0 & 1 & 0.0 \\
\hline Spain & 44.54 & 44 & 43.3 & 90 & 4.0 \\
\hline Southern Europe & 45.39 & 45 & 46.9 & 273 & 12.1 \\
\hline Albania & 46.50 & 46.5 & 50.0 & 2 & 0.1 \\
\hline Bosnia and Herzegovina & 43.00 & 45 & 66.7 & 3 & 0.1 \\
\hline Bulgaria & 39.74 & 40 & 63.2 & 19 & 0.8 \\
\hline Croatia & 42.69 & 42 & 61.4 & 70 & 3.1 \\
\hline Cyprus & 41.71 & 41 & 14.3 & 7 & 0.3 \\
\hline Greece & 46.20 & 47 & 60.0 & 30 & 1.3 \\
\hline Kosovo & 42.00 & 42 & 100.0 & 1 & 0.0 \\
\hline Macedonia & 42.00 & 42 & 80.0 & 5 & 0.2 \\
\hline Montenegro & 42.00 & 42 & 0.0 & 1 & 0.0 \\
\hline Romania & 35.72 & 35 & 77.8 & 54 & 2.4 \\
\hline Serbia & 39.22 & 39 & 78.0 & 41 & 1.8 \\
\hline Slovenia & 42.47 & 41 & 64.9 & 57 & 2.5 \\
\hline Turkey & 40.39 & 38 & 52.9 & 51 & 2.3 \\
\hline South-Eastern Europe & 40.92 & 40 & 64.5 & 341 & 15.2 \\
\hline Armenia & 35.50 & 35.5 & 100.0 & 2 & 0.1 \\
\hline Azerbaijan & 31.00 & 31 & 0.0 & 1 & 0.0 \\
\hline Belarus & 44.00 & 44 & 0.0 & 1 & 0.0 \\
\hline Estonia & 38.73 & 39 & 81.8 & 11 & 0.5 \\
\hline Georgia & 34.00 & 34 & 50.0 & 2 & 0.1 \\
\hline Latvia & 36.41 & 36 & 82.4 & 17 & 0.8 \\
\hline Lithuania & 39.20 & 40 & 53.3 & 15 & 0.7 \\
\hline Moldova & 47.00 & 47 & 0.0 & 1 & 0.0 \\
\hline Russia & 41.79 & 37 & 54.5 & 33 & 1.5 \\
\hline Ukraine & 37.81 & 37 & 70.3 & 37 & 1.6 \\
\hline Eastern Europe & 38.93 & 37 & 65.0 & 120 & 5.3 \\
\hline Total & 43.82 & 44 & 54.3 & 2,247 & 100.0 \\
\hline
\end{tabular}

